\title{
Experimental and Theoretical Investigation of Three Alloy 690 Mockup Components: Base Metal and Welding Induced Changes
}

\author{
Rickard R. Shen, ${ }^{1}$ Bartek Kaplan, ${ }^{2}$ and Pål Efsing ${ }^{1,3}$ \\ ${ }^{1}$ Department of Solid Mechanics, KTH Royal Institute of Technology, 10044 Stockholm, Sweden \\ ${ }^{2}$ Department of Materials Science and Engineering, KTH Royal Institute of Technology, 10044 Stockholm, Sweden \\ ${ }^{3}$ Ringhals AB-Ringhalsverket, 43285 Väröbacka, Sweden
}

Correspondence should be addressed to Rickard R. Shen; rshen@kth.se

Received 7 April 2014; Revised 19 June 2014; Accepted 21 June 2014; Published 3 August 2014

Academic Editor: Qunjia Peng

Copyright (C) 2014 Rickard R. Shen et al. This is an open access article distributed under the Creative Commons Attribution License, which permits unrestricted use, distribution, and reproduction in any medium, provided the original work is properly cited.

\begin{abstract}
The stress corrosion cracking (SCC) resistance of cold deformed thermally treated (TT) Alloy 690 has been questioned in recent years. As a step towards understanding its relevancy for weld deformed Alloy 690 in operating plants, Alloy 690 base metal and heat affected zone (HAZ) microstructures of three mockup components have been studied. All mockups were manufactured using commercial heats and welding procedures in order to attain results relevant to the materials in the field. Thermodynamic calculations were performed to add confidence in phase identification as well as understanding of the evolution of the microstructure with temperature. $\mathrm{Ti}(\mathrm{C}, \mathrm{N})$ banding was found in all materials. Bands with few large $\mathrm{Ti}(\mathrm{C}, \mathrm{N})$ precipitates had negligible effect on the microstructure, whereas bands consisting of numerous small precipitates were associated with locally finer grains and coarser $\mathrm{M}_{23} \mathrm{C}_{6}$ grain boundary carbides. The Ti(C,N) remained unaffected in the HAZ while the $\mathrm{M}_{23} \mathrm{C}_{6}$ carbides were fully dissolved close to the fusion line. Cold deformed solution annealed Alloy 690 is believed to be a better representation of this region than cold deformed TT Alloy 690.
\end{abstract}

\section{Introduction}

Many components in pressurized water reactors (PWRs) today are made of Ni-base alloys, for example, control rod drive mechanism (CRDM) nozzles, steam generator (SG) tubing, and SG divider plates. These components were previously made of Alloy 600 since it had exhibited good corrosion resistance in many aggressive environments in combination with having a coefficient of thermal expansion close to that of steel. Unfortunately, Alloy 600 soon turned out to be susceptible to stress corrosion cracking (SCC) in primary water, having a case reported in field in 1971 after only two years in service [1].

Alloy 690 was developed as a remedy to the SCC in Alloy 600, essentially being a high $\mathrm{Cr}$ version of Alloy 600 containing nominally $30 \% \mathrm{Cr}$ instead of around $15-16 \%$. Since the SCC resistance of Alloy 600 was found to significantly increase after being thermally treated (TT) [2-4], that is, heat treated for precipitation of a semicontinuous carbide network along the grain boundaries, Alloy 690 has also been used in the TT state. TT Alloy 690 has been used in operating plants since 1989, and no cracking due to SCC has been reported to date. From both operational experience and laboratory experiments, it is evident that Alloy 690 has considerably higher SCC initiation resistance than its predecessor [2-4]. Experiments in recent years have however shown that it is possible to induce high SCC crack propagation rates in simulated primary water, comparable to those of Alloy 600, but only when the tested material had been heavily cold worked prior to testing, for example, by cold rolling or forging [5-7].

Earlier experiments on cold worked TT Alloy 690 were part of an exploration of the effects of plastic strain on SCC in primary water. While Alloy 690 is not used in an intentionally cold worked state, the experiments were instead motivated by the concern for the heat affected zone (HAZ) of welded Alloy 690, which experiences high levels of plastic straining due to weld shrinkage, and can be further increased by repair welds. Estimates based on electron backscattered diffraction (EBSD) measurements have shown that the effective plastic 


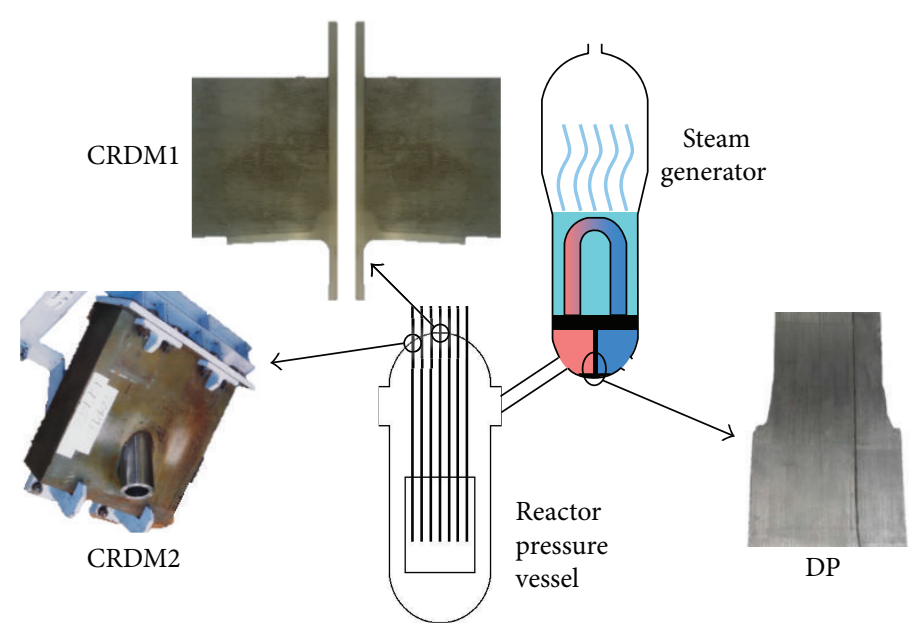

FIGURE 1: The mockups denoted by CRDM1 and CRDM2 represented reactor pressure vessel head CRDM nozzle penetrations, and DP represented the lower part of the divider plate that separates the hot and cold sides of the SG.

strain in the HAZ typically increases towards a maximum around the fusion line $[7,8]$. The maximum can often reach levels comparable with $20-30 \%$ thickness reduction by cold rolling or forging, that is, the levels of deformation for which high crack growth rates have been observed in experiments.

Although cold working TT Alloy 690 base metal can generate a material with similar hardness and dislocation density as in the HAZ, the microstructural changes caused by the thermal cycles of a welding process would be absent. It has been shown that cold working Alloy 690 in a solution annealed (SA) state, where the $\mathrm{M}_{23} \mathrm{C}_{6}$ carbides have been dissolved, is not nearly as detrimental to SCC resistance as the same cold work performed in the TT state, where the grain boundaries would instead be densely covered in carbides $[7,9,10]$. Recent SCC crack growth experiments on the Alloy $690 \mathrm{HAZ}$ itself also show much lower crack growth rates than in cold worked TT Alloy 690 base metals despite the high innate plastic strains of the $\operatorname{HAZ}[7,11]$. The results suggest that plastic strain by itself cannot explain the high crack growth rates. Synergetic effects of cold work and microstructural features, for example, banding phenomena, cracking of intergranular carbides, and strain localization at grain boundaries, have thus attracted increased attention in recent years $[9,12,13]$.

How the differences in strain and thermal history affect the microstructure is an important step in understanding to which extent results obtained using cold worked materials can be extrapolated to describe HAZ behavior. The microstructure in the cold worked state has been described in literature and often exhibits damage such as cracked particles, particle-matrix interface debonding, grain boundary cavitation, or strain localization at particles and grain boundaries $[9,10,13]$. In this work, thick-walled TT Alloy 690 base metals without addition of cold work have been characterized along with their respective HAZs using materials representative to those found in operating plants. The aim of this work was to identify the microstructural changes induced by welding and discuss the suitability of using cold worked TT Alloy 690 to simulate the HAZ. In order to attain a complete picture of the alloy, the equilibrium composition and fractions of the constituent phases were also investigated using thermodynamic calculations and compared with the experimental observations.

\section{Experimental Details}

2.1. Fabrication of Mockups. Segments of three mockup components from different manufacturers were provided for this work. All three mockups have been produced using commercial heats, realistic designs, and welding procedure specifications approved for actual plant components. Any observations made in this work are therefore expected to be found in materials in operating plants as well. Figure 1 shows photos of the mockups and what they represent in a PWR plant. In this work, the three mockups are referred to as

(i) CRDM1-CRDM nozzle penetration mockup with the Alloy 690 tube inserted straight through a low alloy steel plate,

(ii) CRDM2-CRDM nozzle penetration mockup with the Alloy 690 tube inserted at a $46.5^{\circ}$ angle through a low alloy steel plate,

(iii) $\mathrm{DP}$ - a one inch thick cross-sectional slice of an Alloy 690 SG divider plate mockup.

All Alloy 690 base metals were welded in the as-received state, that is, hot worked followed by a SA and TT. The SA aimed at dissolving the carbides and is typically performed at around $1050^{\circ} \mathrm{C}$ for up to an hour followed by a water quench. The purpose of the TT is to precipitate carbides at the grain boundaries, which is achieved by several hours at around $700^{\circ} \mathrm{C}$. These heat treatments also serve to recover the material and to relieve elastic stresses. The chemical compositions of the Alloy 690 base metals which used the mockups are given in Table 1 .

CRDM1 was manufactured using a hot extruded TT Alloy 690 tube inserted straight through a SA 533 grade B steel plate that was clad in grade $308 \mathrm{~L}$ stainless steel on the 
TABLE 1: Chemical compositions in mass-\% of the Alloy 690 base metals used in the mockups.

\begin{tabular}{lccccccccccc}
\hline Base metal & $\mathrm{Ni}$ & $\mathrm{Cr}$ & $\mathrm{Fe}$ & $\mathrm{C}$ & $\mathrm{Si}$ & $\mathrm{Mn}$ & $\mathrm{P}$ & $\mathrm{S}$ & $\mathrm{N}$ & $\mathrm{Ti}$ & $\mathrm{Al}$ \\
\hline CRDM1 tube & Bal. & 29.5 & 10.0 & 0.020 & 0.28 & 0.31 & 0.007 & 0.001 & 0.040 & 0.35 & 0.18 \\
CRDM2 tube & Bal. & 30.0 & 8.9 & 0.020 & 0.32 & 0.30 & 0.007 & 0.001 & 0.028 & 0.21 & 0.38 \\
DP bar & Bal. & 29.0 & 9.1 & 0.018 & 0.30 & 0.26 & 0.003 & 0.001 & 0.023 & 0.33 & 0.39 \\
\hline
\end{tabular}

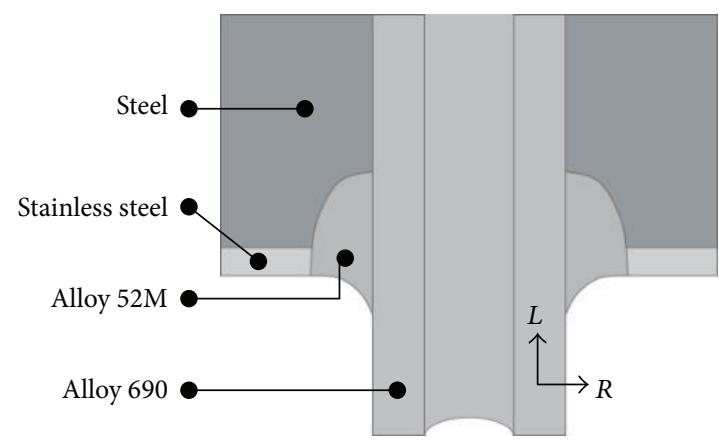

(a)

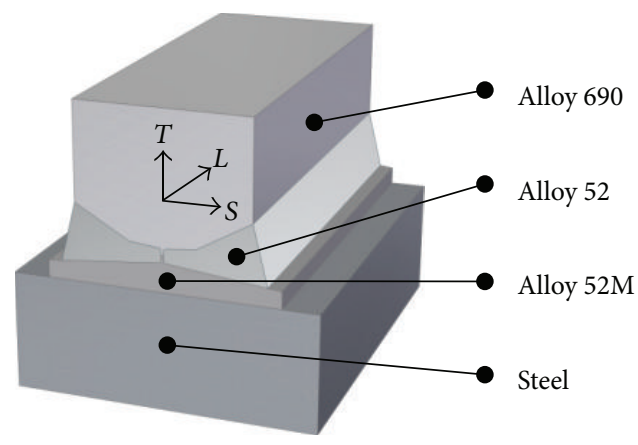

(b)

FIGURE 2: Schematic sketches of (a) CRDM1 and (b) DP.

simulated internal surface, representing the reactor pressure vessel head. The tube had an outer diameter of $100 \mathrm{~mm}$ and a wall thickness of $16 \mathrm{~mm}$. The tube was attached to the steel plate by gas tungsten arc welding (GTAW) with Alloy $52 \mathrm{M}$ using a J-groove weld. A schematic sketch of the Jgroove weld is shown in Figure 2(a). The completed weld was inspected using penetrant testing (PT) and ultrasonic testing (UT).

CRDM2 was manufactured in a similar manner as CRDM1, but by a different manufacturer, and using a TT Alloy 690 tube inserted at a $46.5^{\circ}$ angle through an SA 508 grade 3 steel plate instead of straight through. The tube was also hot extruded and had similar dimensions as the CRDM1 tube. Furthermore, no stainless steel cladding was applied on the steel plate, and Alloy 52 was used to fill the J-groove weld of this mockup. The completed weld joint was inspected using PT and UT.

The DP mockup had a steel bar as a base, representing the bottom end of a SG, buttered with a roughly $2 \mathrm{~cm}$ thick layer of Alloy $52 \mathrm{M}$. A hot forged bar of TT Alloy 690 was used to represent a SG divider plate. The bar was $132 \mathrm{~mm}$ thick in the S-direction, $105 \mathrm{~mm}$ in the T-direction, and roughly $410 \mathrm{~mm}$ long. The TT Alloy 690 bar was oriented as shown in Figure 2(b) and welded to the steel bar by GTAW with Alloy 52 using a double beveled groove. The completed weld was inspected using PT and UT.

2.2. Microstructural Characterization. In this work, the longitudinal, circumferential, and radial directions have been denoted by $\mathrm{L}, \mathrm{C}$, and $\mathrm{R}$, respectively, for the tube materials. For the TT Alloy 690 bar used in DP, the longitudinal, long-transverse, and short-transverse directions have been denoted by $\mathrm{L}, \mathrm{T}$, and $\mathrm{S}$, respectively. In order to study the possibility of microstructural anisotropy in the base metal, metallographic specimens were prepared with planes normal to the three orthogonal directions mentioned above.
For characterization of the unaffected base metal, material sampled far from the weld was used to ensure minimal influence from the weld process. Specimens for HAZ characterization were prepared using material sampled near the weld root, where the weld induced plastic strains typically are significant. All samples were cut out of the mockups with care using plenty of coolant and low cutting speed to avoid unwanted evolution of heat.

The sampled materials were mounted in conductive plastic resin, ground on $\mathrm{SiC}$ paper, and polished on a rotating cloth disc with diamond suspension. The samples were investigated both in the as-polished condition and after being electrolytically etched in a nital solution (5\% nitric acid in ethanol) with $4 \mathrm{~V}$ applied anodically for 15-25 s. The samples were studied in a light optical microscope (LOM) with optional dark field filter and in a scanning electron microscope (SEM) equipped with a backscattered electron (BSE) detector and equipment for energy dispersive X-ray spectroscopy (EDX).

Apart from the matrix, $\mathrm{M}_{23} \mathrm{C}_{6}$ type $\mathrm{Cr}$-rich carbides and $\mathrm{TiN} / \mathrm{Ti}(\mathrm{C}, \mathrm{N})$ precipitates were assumed to be the only phases of significance in the material. These were differentiated in LOM by their color since $\mathrm{TiN} / \mathrm{Ti}(\mathrm{C}, \mathrm{N})$ appear golden or orange, while the $\mathrm{Cr}$-rich carbides appear grey. High enough magnification is important as both phases appear as dark spots at insufficient magnification. They were also differentiated in SEM by atomic number contrast. The average atomic number of $\mathrm{Ti}(\mathrm{C}, \mathrm{N})$ is significantly lower than $\mathrm{M}_{23} \mathrm{C}_{6}$, which results in a much darker color in the SEM using a BSE detector. EDX was used as a supplement in SEM to confirm locally elevated $\mathrm{Ti}$ or $\mathrm{Cr}$ levels at the particles for additional confidence in the phase identification.

Uneven illumination caused by the light source, lens system, and camera, for example, vignetting and hue gradients across the image, can affect the perception of hues in the LOM micrographs. The illumination over the image was quantified 
by fitting a second-order polynomial surface to the pixel intensities for each of the red, green, and blue color channels, respectively, over the image. Since Alloy 690 has a single phase matrix, such a fit of an ideal image would result in a flat plane for each color channel. All three fits would also be of similar intensity since they represent the grey color of the matrix. For each color channel, the fitted surface was divided by its mean value over the image to obtain a normalized division filter, which was used to compensate for the uneven illumination. Note that this method does not introduce any artifacts to, nor remove any details from, the images.

\section{Thermodynamic Calculations}

Thermodynamic calculations were applied in the present work in order to investigate the equilibrium phase fractions and the composition of each individual phase, with focus on the $\mathrm{M}_{23} \mathrm{C}_{6}$ carbide and the $\mathrm{Ti}(\mathrm{C}, \mathrm{N})$ nitride/carbonitride precipitates. The considered alloy compositions were the same as shown in Table 1, excluding Mn, $\mathrm{S}$, and $\mathrm{P}$ as explained below.

The thermodynamic calculations presented in this work were performed using the Thermo-Calc software package [14] together with the Ni-based Superalloys database version 5 (TCNI5) available from Thermo-Calc Software. The database contains critically assessed thermodynamic parameters that make up the Gibbs energy of each phase as a function of temperature, pressure, and composition. Roughly, the calculations are based on minimization of the Gibbs energy functions of the system subject to some user defined constraints to find, for example, the fractions and composition of phases present when the equilibrium state is achieved. These quantities, as well as many others, can then be visualized as a function of, for example, temperature or average composition.

Calculations such as these are strongly limited by the quality of the database used, which is why the choice of database is critical. In the case of TCNI5, the database does not include $\mathrm{Mn}, \mathrm{P}$, and S. However, these elements are only present in small quantities in the investigated alloys and were assumed to have little or no effect on the stability of the phases of interest.

\section{Results and Discussion}

4.1. Unaffected Base Metal. The TT Alloy 690 tube of CRDM1 was homogeneous and had an equiaxed grain structure with plenty of annealing twins. The grain boundaries were densely covered by a network of $\mathrm{Cr}$-rich carbides. Intragranular carbides were observed but very rarely. It is commonly accepted that these Cr-rich carbides in Alloy 690 are of the $\mathrm{M}_{23} \mathrm{C}_{6}$ type $[2,15]$, which agrees well with the thermodynamic calculations; see Section 4.3. Fairly large faceted precipitates of sizes up to around $10 \mu \mathrm{m}$ were common in the microstructure and appeared orange in LOM as shown in Figure 3. These are generally accepted as $\mathrm{TiN}$ or $\mathrm{Ti}(\mathrm{C}, \mathrm{N})$. Since Lengauer et al. have shown that pure TiN has a golden color, which it gradually loses as carbon content increases [16], these precipitates will be denoted by $\mathrm{Ti}(\mathrm{C}, \mathrm{N})$ in this work.
TABLE 2: EDX analyses of matrix and second phase particles in mass$\%$. The scans of the particles were strongly affected by the matrix, but the elevated $\mathrm{Cr}$ and $\mathrm{Ti}$ levels for respective phase were still very clear.

\begin{tabular}{lccccc}
\hline Phase & $\mathrm{Ni}$ & $\mathrm{Cr}$ & $\mathrm{Fe}$ & $\mathrm{Ti}$ & Other \\
\hline Matrix & 58.10 & 30.09 & 8.57 & $\mathrm{ND}$ & Balance \\
$\mathrm{M}_{23} \mathrm{C}_{6}$ & 13.08 & $\mathbf{7 5 . 6 0}$ & 2.88 & $\mathrm{ND}$ & Balance \\
$\mathrm{Ti}(\mathrm{C}, \mathrm{N})$ & 24.85 & 18.75 & 4.28 & $\mathbf{3 6 . 9 2}$ & Balance \\
\hline
\end{tabular}

$\mathrm{ND}=$ not detected.

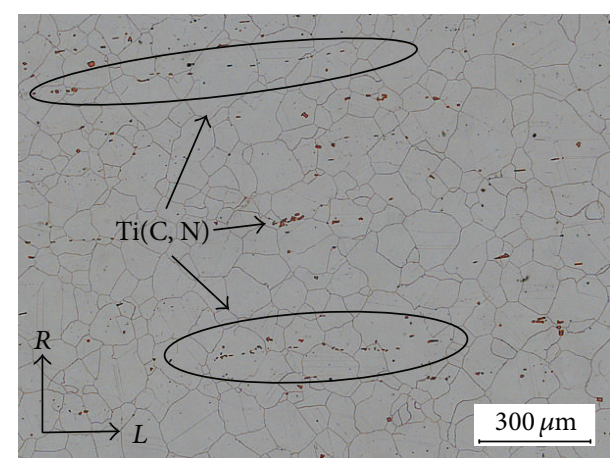

Figure 3: Microstructure of the CRDM1 tube. Ti(C,N) precipitates, visible as orange or dark spots, were common and tended to gather in faint streaks along the L-direction.

The $\operatorname{Ti}(\mathrm{C}, \mathrm{N})$ precipitates were often found concentrated in bands extending in the L-direction of the tube. These bands were nonetheless faint in this material and easily missed. Many of the precipitates also appeared elongated in shape along the L-direction. Virtually no free oxide inclusions were observed in the base metal, although oxide slags were frequently found at the core of the larger $\mathrm{Ti}(\mathrm{C}, \mathrm{N})$ precipitates.

The microstructure of the TT Alloy 690 tube of CRDM2 was similar to that of the tube of CRDM1, having an equiaxed grain structure with plenty of annealing twins and with grain boundaries densely decorated by carbides. Large $\operatorname{Ti}(\mathrm{C}, \mathrm{N})$ precipitates of comparable size as those in CRDM1 were also present, but fewer in number. The differences between these tubes were mainly related to particle banding, which was significantly more distinct in this tube than in CRDM1. In particular, the bands contained plenty of small intragranular particles, up to around $1 \mu \mathrm{m}$ in diameter, in addition to the large $\operatorname{Ti}(\mathrm{C}, \mathrm{N})$ precipitates. As can be seen in Figure 4, the bands were extending in the L-direction as columns. These bands were especially easy to see in LOM using a dark field filter. Note also that the banding can be difficult to see if the material is only sectioned in the R-C-plane.

The small intragranular particles in the bands were also believed to be $\mathrm{Ti}(\mathrm{C}, \mathrm{N})$. They also had an orange color in LOM, and EDX confirmed clearly elevated Ti levels at these particles. Table 2 shows the distinct difference in $\mathrm{Cr}$ and $\mathrm{Ti}$ levels for these two types of particles, although their limited sizes did not allow for a quantitative chemical analysis. The $\mathrm{Ti}(\mathrm{C}, \mathrm{N})$ also appeared noticeably darker in SEM using a BSE detector compared to $\mathrm{M}_{23} \mathrm{C}_{6}$ carbides, agreeing well with it being a phase with lower average atomic number. Despite the large number of fine $\mathrm{Ti}(\mathrm{C}, \mathrm{N})$ precipitates, the total volume 


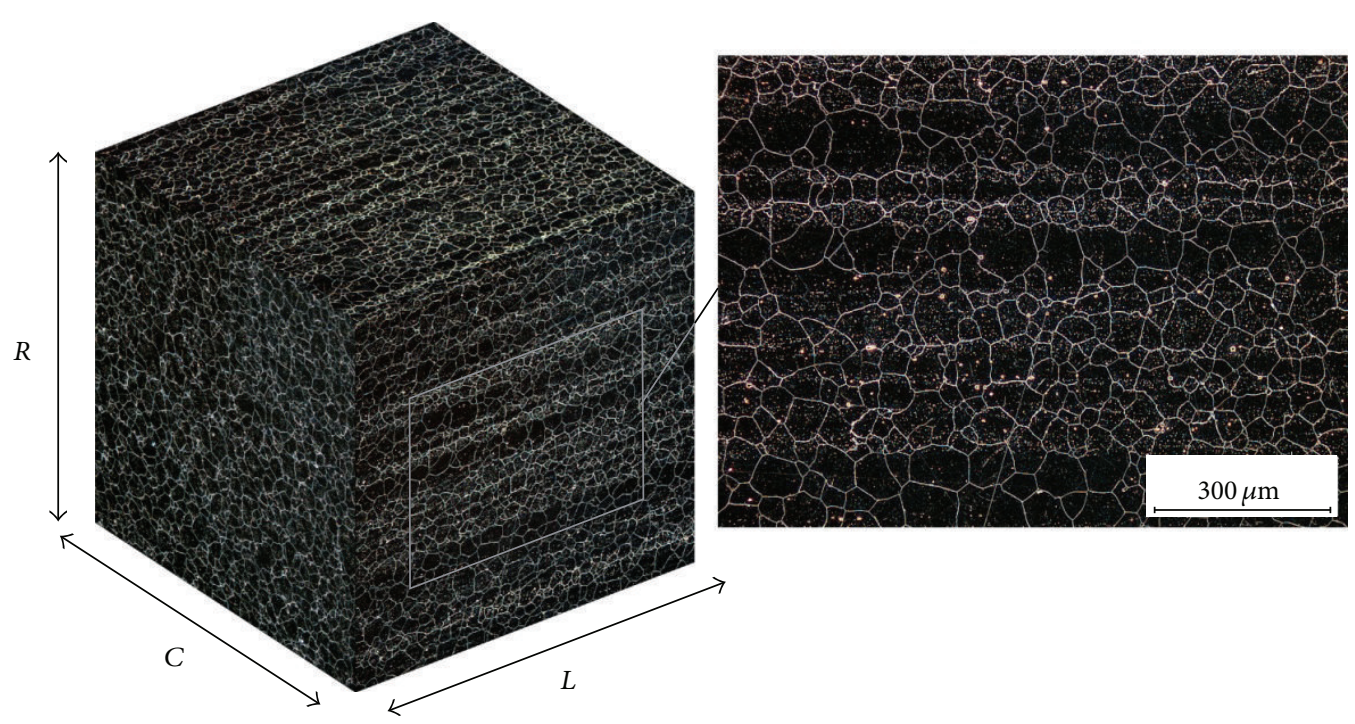

FIgURE 4: Bands of small TiN precipitates extend along the L-direction in the CRDM2 tube.

fraction of this phase still appeared to be less than in CRDM1 due to a lower number of large $\mathrm{Ti}(\mathrm{C}, \mathrm{N})$ precipitates. This correlates well with the lower $\mathrm{N}$ and Ti content in the CRDM2 tube shown in Table 1.

The grain size tended to be smaller within the $\operatorname{Ti}(\mathrm{C}, \mathrm{N})$ banded regions. This resulted in a bimodal grain size distribution in the CRDM2 tube, although the average grain size was comparable to that of the CRDM1 tube. Grain boundaries could be seen lining up along bands fairly commonly, forming relatively straight lines ranging up to around $1 \mathrm{~mm}$; see Figure 5. This sort of grain boundary alignment was observed throughout the material, but always within a band, or along the edge of a band. These observations indicate that $\mathrm{Ti}(\mathrm{C}, \mathrm{N})$ precipitates may have affected recrystallization during hot work, possibly by acting as strain localizers and thereby increasing the number of nucleation sites for recrystallization or by grain boundary pinning to hamper growth of recrystallized grains. Whether or not such a linearization of grain boundaries affects SCC crack propagation rates has not been treated in this work, but it is clear that an intergranular crack path would be locally less tortuous.

Observing the grain boundaries at high magnification in LOM revealed that the grain boundary carbides within the $\operatorname{Ti}(\mathrm{C}, \mathrm{N})$ bands were coarse, which can be seen in Figure 6. In contrast, the parts of grain boundaries lying outside the banded regions were covered by fine carbides. Transitions from fine to coarse carbides in the middle of a grain boundary were observed, which shows that this observation was related to the banded region rather than the grain boundary misorientation. The same was observed on as-polished specimen in SEM using a BSE detector. This shows that the size difference is not an etching effect.

The microstructure of the DP bar is shown in Figure 7 and was the least homogeneous of the three investigated TT Alloy 690 materials. The microstructure was severely banded with small intragranular $\mathrm{Ti}(\mathrm{C}, \mathrm{N})$ in the same way as the CRDM2 tube. The grains were coarser than in both the tube materials

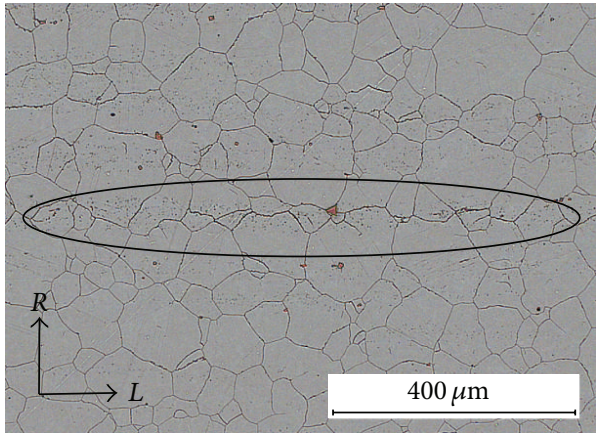

FIgURE 5: Grain boundaries in the CRDM2 tube occasionally line up to form fairly straight lines within bands or along the edge of a band.

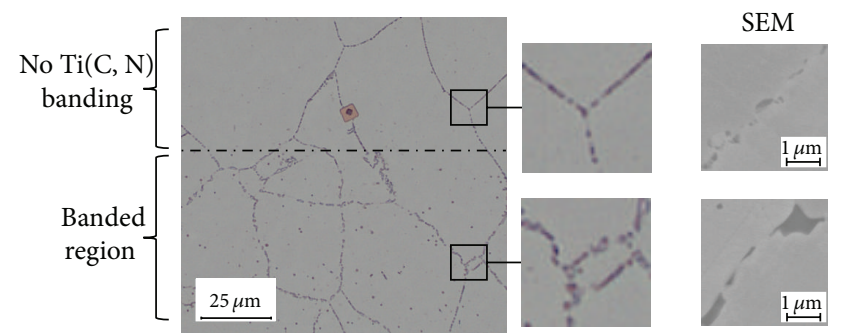

FIGURE 6: Grain boundary carbides located within regions banded with small $\mathrm{Ti}(\mathrm{C}, \mathrm{N})$ in the CRDM2 tube were noticeably coarser than carbides located in the regions free of fine $\mathrm{Ti}(\mathrm{C}, \mathrm{N})$ particles.

but were still equiaxed with plenty of fine carbides along the grain boundaries outside the banded regions. As in the CRDM2 tube, the grain boundary carbides within the banded regions were noticeably coarser. The tendency for reduced grain size in the banded regions was also observed in this material. 

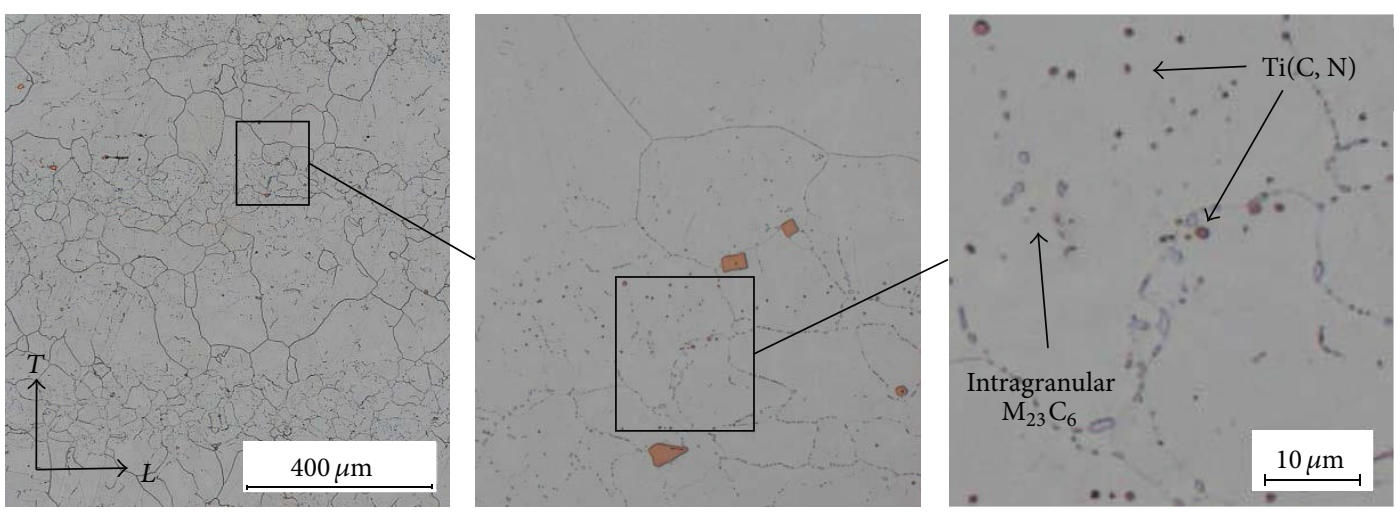

FIgURE 7: The TT Alloy 690 DP bar had coarse grains and showed carbide coarsening associated with Ti(C,N) banding just like the CRDM2 tube. The magnification shows that the intragranular particle banding consisted of mainly orange $\mathrm{Ti}(\mathrm{C}, \mathrm{N})$ precipitates and also of grey $\mathrm{M}_{23} \mathrm{C}_{6}$ carbides.

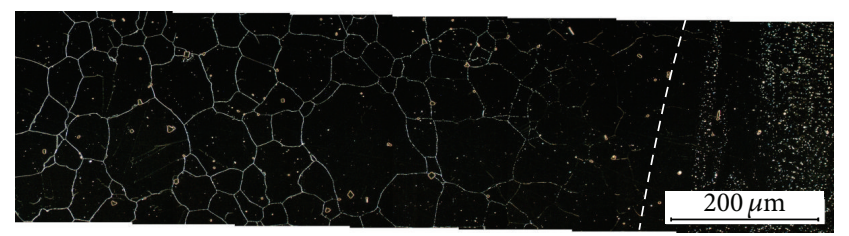

FIGURE 8: These stitched LOM images show the HAZ of the CRDM1. The $\mathrm{M}_{23} \mathrm{C}_{6}$ carbides closest to the fusion line, marked by the dashed line, have been dissolved.

Unlike the CRDM2 tube, coarse $\mathrm{M}_{23} \mathrm{C}_{6}$ carbides of a significant amount were also present intragranularly in the banded regions. High magnification is required to differentiate $\mathrm{M}_{23} \mathrm{C}_{6}$ and $\mathrm{Ti}(\mathrm{C}, \mathrm{N})$ in LOM. If the resolution is insufficient, both types of particles appear as dark spots which can lead to erroneous phase identification.

4.2. Heat Affected Zone. The HAZ of the Alloy 690 base metals from all three mockups showed a trend of $\mathrm{M}_{23} \mathrm{C}_{6}$ carbide dissolution close to the fusion line. Approaching the fusion line from the unaffected base metal, the carbide distribution changed from the initial semicontinuous network of fine $\mathrm{M}_{23} \mathrm{C}_{6}$ carbides into discrete and slightly coarser particles. Further approaching the fusion line, the $\mathrm{M}_{23} \mathrm{C}_{6}$ carbides were absent in LOM. Since the nital etchant is less effective in carbide-free grain boundaries in Alloy 690 [4], this region was only faintly etched. The apparently carbide-free zone typically spanned $100-500 \mu \mathrm{m}$ wide depending on mockup. The full transition from unaffected grain boundary carbides to the full dissolution near the fusion line in the CRDM1 tube can be seen in Figure 8. Surprisingly, neither of the tube materials exhibited noticeable grain growth in the HAZ.

In the region where the grain boundary carbides appeared dissolved in LOM, only the occasional intergranular carbides could be seen in SEM, but only along some of the grain boundaries, and generally of very fine size. An example from the CRDM2 tube is shown in Figure 9(a), where the carbides are just barely visible, which can be compared with the grain boundary of the unaffected base metal at the same magnification shown in Figure 9(b). It is not clear if these carbides remained partially undissolved or if they were precipitated after the initial weld pass. Either way these carbides should not have experienced temperatures high enough for dissolution since the initial weld pass but have had the opportunity to grow due to the thermal cycles of the subsequent weld passes. In other words, they were likely to be both smaller and fewer during the weld induced straining of the initial weld pass. Thus, it is reasonable to believe that their presence was negligible, from a micromechanical point of view, during the straining.

The microstructure in the carbide-free region would have been similar to that of SA Alloy 690 during the weld induced straining. Since the plastic strains typically are the highest near the fusion line, it is possible that cold working Alloy 690 in the SA state yields a better representation of weld deformed HAZ than cold working it in the TT state. This may explain why SCC crack growth experiments on HAZ specimens have shown crack growth rates closer to specimens of Alloy 690 cold worked in the SA state than those cold worked in the TT state.

The previously mentioned coarser carbides in the bands of CRDM2 and DP appear to have been less affected by the weld. Compared to the carbides outside the bands, the coarser carbides within the bands appear to stay undissolved closer to the fusion line, as can be seen in Figure 10. Since a weld pass is a brief heat treatment, it is possible that slow kinetics did not permit a full dissolution of the coarser carbides. A large portion of the dissolved carbon would then have existing carbide surfaces to redeposit on during cooling or during the subsequent weld passes. Closer to the fusion line, however, even the coarsest of the carbide particles seem to have been fully dissolved.

Unlike the $\mathrm{M}_{23} \mathrm{C}_{6}$ carbides, the Ti(C,N) bands of CRDM2 and DP were not noticeably affected by the thermal cycles of the welding process, as can be seen in Figure 10. The Ti(C,N) precipitates remain, and in some cases the larger $\mathrm{Ti}(\mathrm{C}, \mathrm{N})$ precipitates from the base metal could even be found in the weld metal. Even so, the weld induced strains did not cause cracked carbides or $\mathrm{Ti}(\mathrm{C}, \mathrm{N})$ precipitates in the HAZ of any 


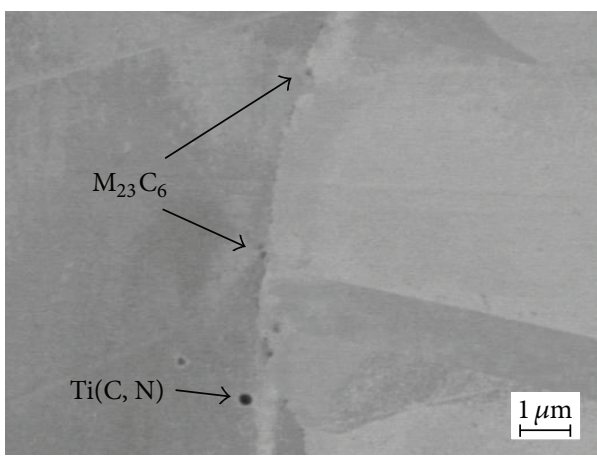

(a)

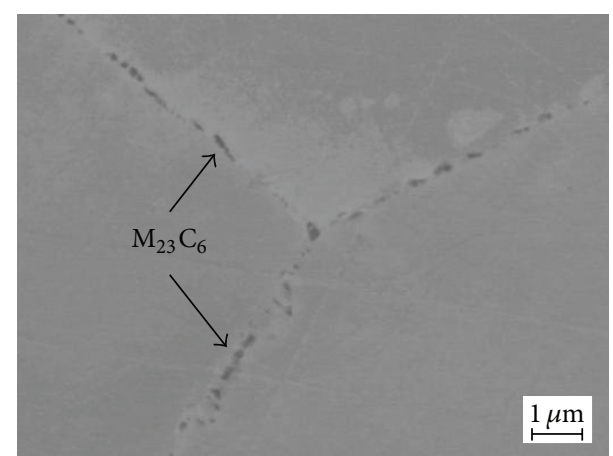

(b)

FiguRE 9: (a) Intergranular carbides were rare in the carbide-dissolution region. They were not observed on all grain boundaries and were very small. This can be compared with (b) the unaffected base metal.

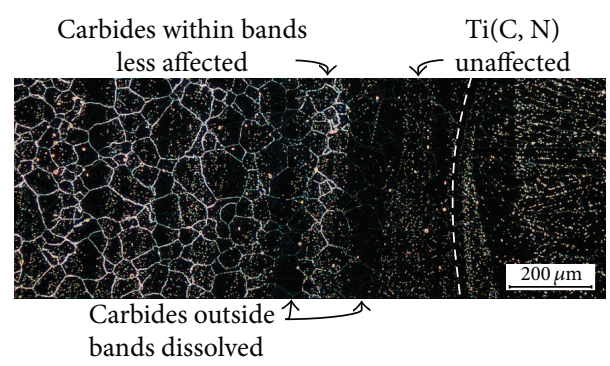

Figure 10: The HAZ of CRDM2 with the fusion line marked by a dashed line. Coarser carbides seem to have been less affected by the weld than finer carbides. Ti(C,N) precipitates appear unaffected.

of the mockups, unlike in heavily cold rolled TT Alloy 690 where this type of damage is common $[9,10,13]$.

\subsection{Calculated Equilibrium Fractions and Composition of} Phases. The thermodynamic calculations verify that the intragranular precipitates, usually referred to as $\mathrm{TiN}$ in the literature, in fact correspond to a carbonitride while in equilibrium with the matrix phase in solid state. The composition of the phase $\mathrm{Ti}(\mathrm{C}, \mathrm{N})$ at $1000^{\circ} \mathrm{C}$ based on the alloy composition of the CRDM1 tube is shown in Table 3. The main dissolved element was found to be $\mathrm{Cr}$ ( $\sim 0.6$ mass$\%$ ) while $\mathrm{Fe}, \mathrm{Ni}, \mathrm{Si}$, and $\mathrm{Al}$ were present only as trace quantities $\left(10^{-6}\right.$ mass- $\%$ or less). The solubility of $\mathrm{Cr}$ in $\mathrm{Ti}(\mathrm{C}, \mathrm{N})$ increased slightly with temperature up to 0.9 mass\%, 2 mass-\%, or 1 mass-\% for alloys CRMD1, CRDM2, and DP, respectively. Otherwise, the composition of metallic elements in this phase was more or less constant.

However, the $\mathrm{C} / \mathrm{N}$ ratio varied strongly with temperature, as shown in Figure 11. Note that the composition corresponds to $\mathrm{TiN}$ at temperatures where the matrix was fully molten, that is, where the $\mathrm{TiN} / \mathrm{Ti}(\mathrm{C}, \mathrm{N})$ phase was in equilibrium with the liquid phase. Note that this means that for all three Alloy 690 compositions, the $\mathrm{Ti}(\mathrm{C}, \mathrm{N})$ phase was calculated to be fully dissolved only when above the temperature at which the matrix would be fully molten. This effect was most prominent for the CRDM1 alloy where the $\operatorname{Ti}(\mathrm{C}, \mathrm{N})$ phase was fully
TABLE 3: Calculated chemical composition of the Ti(C,N) phase at $1000^{\circ} \mathrm{C}$ for the CRDM1 overall material composition.

\begin{tabular}{lcccc}
\hline Element (mass-\%) & $\mathrm{Ti}$ & $\mathrm{N}$ & $\mathrm{C}$ & $\mathrm{Cr}$ \\
\hline $\mathrm{Ti}(\mathrm{C}, \mathrm{N})$ & $\mathrm{Bal}$ & 16.5 & 5.2 & 0.6 \\
\hline
\end{tabular}

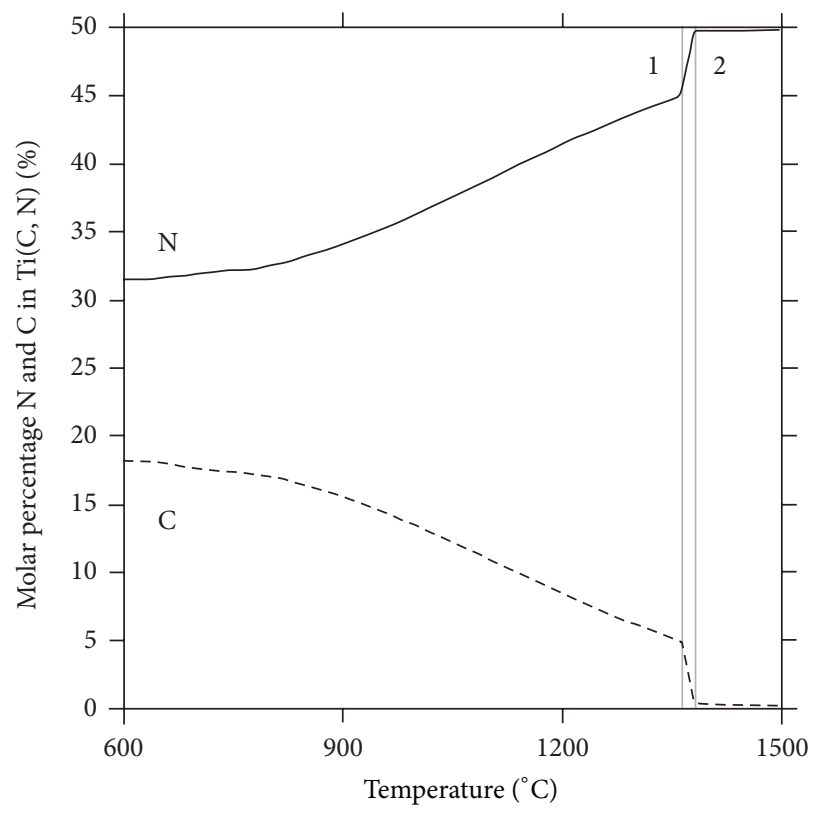

FIgUre 11: The $\mathrm{N}$ (solid line) and $\mathrm{C}$ (dashed line) content in $\mathrm{Ti}(\mathrm{C}, \mathrm{N})$ given in mole fraction as a function of temperature. The temperature for incipient melting of the matrix phase is marked by the number 1 and for full melting of the matrix by the number 2 . The two vertical lines indicate the melting interval of the matrix phase.

dissolved at $1487^{\circ} \mathrm{C}$, which is over 100 degrees higher than the calculated melting temperature of the matrix phase, that is, at $1381^{\circ} \mathrm{C}$. Furthermore, according to the calculations the melting interval of the matrix phase was the same for all three compositions; see Figure 12.

The main differences between the mockup alloys were the total phase fractions of $\operatorname{Ti}(\mathrm{C}, \mathrm{N})$ and the temperature at which 


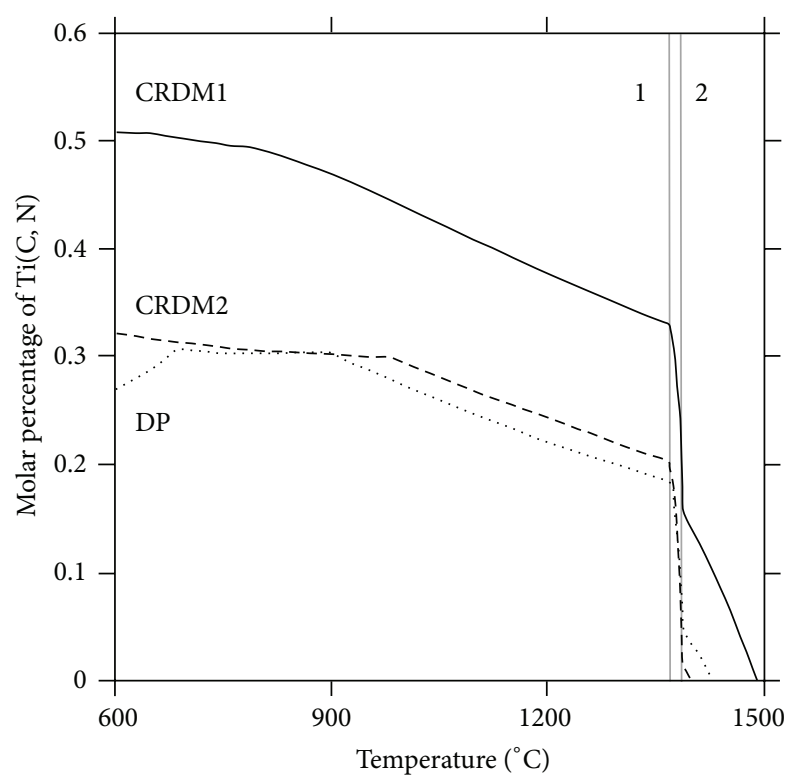

FIgUre 12: Mole fraction of $\mathrm{Ti}(\mathrm{C}, \mathrm{N})$ at equilibrium as a function of temperature for the three Alloy 690 compositions. The incipient melting of the matrix phase is indicated by the number 1 . In all cases, the $\operatorname{Ti}(\mathrm{C}, \mathrm{N})$ phase is stable up to and above the temperature of complete melting of the matrix, which is indicated by the number 2.

$\operatorname{Ti}(\mathrm{C}, \mathrm{N})$ was fully dissolved in the liquid. This means that a complete solid solution of all elements into the matrix is not possible for any of the investigated alloys, if the calculations are to be trusted. Thus any heat treatment performed at solid state temperatures, or at insufficient superheating above the melting temperature of the matrix, will leave a certain fraction of undissolved $\mathrm{TiN} / \mathrm{Ti}(\mathrm{C}, \mathrm{N})$ in the microstructure. Figure 12 also shows that little dissolution occurs at solid state temperatures, which means that the $\mathrm{Ti}(\mathrm{C}, \mathrm{N})$ precipitates would remain essentially unaffected in the HAZ. These results are consistent with the observed microstructures near the fusion line (Figures 8 and 9), where the number of $\mathrm{Ti}(\mathrm{C}, \mathrm{N})$ particles was still large while the $\mathrm{M}_{23} \mathrm{C}_{6}$ carbides were dissolved and did not notably reprecipitate during solidification after welding and the thermal cycles of subsequent weld passes. Furthermore, the higher phase fraction of $\mathrm{Ti}(\mathrm{C}, \mathrm{N})$ in CRDM1 agrees well with the observations in LOM.

The temperature for full dissolution of the Cr-rich $\mathrm{M}_{23} \mathrm{C}_{6}$ phase was calculated to be $781^{\circ} \mathrm{C}$ for CRDM1. Only Fe and $\mathrm{Ni}$ were, to a small extent ( $\sim 1-2$ mass-\%), dissolved in the carbide and the composition of this phase was more or less unaffected by the temperature. For the CRDM2 alloy, the dissolution temperature was calculated to be $983^{\circ} \mathrm{C}$ and for the DP alloy $889^{\circ} \mathrm{C}$. Furthermore, the $\mathrm{M}_{23} \mathrm{C}_{6}$ carbide in CRDM2 also dissolved up to 4 mass- $\% \mathrm{Ni}$ and 2.4 mass- $\% \mathrm{Fe}$ and up to 9 mass-\% Ni and 3.5 mass-\% Fe in the DP alloy at higher temperatures.

A Cr-rich (95-96 mass-\%) phase with body centered cubic (BCC) crystal structure was calculated to be stable below $\sim 770-780^{\circ} \mathrm{C}$ for all three alloy compositions but was not observed in the samples. However, the $\mathrm{M}_{23} \mathrm{C}_{6}$ carbide was also stable in this temperature range and could be identified in the samples presented in Section 2. This could be due to the slower substitutional diffusion mechanism, which is required to form the BCC phase, while $\mathrm{M}_{23} \mathrm{C}_{6}$ may form locally by interstitial diffusion of C. Furthermore, the BCC phase could be difficult to find due to the low atomic number contrast when investigating the microstructure with SEM-BSE. On the other hand, to the best of the authors' knowledge, the BCC phase has not been observed in Alloy 690 during any EBSD or transmission electron microscopy (TEM) studies either. It is therefore possible that the stability of this phase is overestimated in the thermodynamic database used.

\section{Conclusions}

Particle banding was observed in the TT Alloy 690 base metal of all three mockups investigated in this work. In samples from CRDM2 and DP, the bands consisted mainly of fine $\mathrm{Ti}(\mathrm{C}, \mathrm{N})$ precipitates. In these samples the $\mathrm{Ti}(\mathrm{C}, \mathrm{N})$ bands were associated with locally finer grain sizes and coarser intergranular carbides. Furthermore, the grain boundaries tended to line up along the bands, which reduced the intergranular path tortuosity in the materials' respective longitudinal direction. The TT Alloy 690 samples from CRDM1 had the highest volume fraction of the $\mathrm{Ti}(\mathrm{C}, \mathrm{N})$ phase but these particles were distributed as fewer large precipitates instead of many fine ones. In this material, the particle banding had negligible effects on the base metal microstructure.

The thermodynamic calculations showed that the equilibrium composition of the $\mathrm{Ti}(\mathrm{C}, \mathrm{N})$ phase corresponds to $\mathrm{TiN}$ at temperatures where the matrix is fully molten. According to the calculations, the $\mathrm{Ti}(\mathrm{C}, \mathrm{N})$ in the $\mathrm{HAZ}$ would remain essentially unaffected by the heat from welding, which is verified by the observed microstructure near the fusion line. The calculations also indicated stability of a Cr-rich BCC phase below roughly $770-780^{\circ} \mathrm{C}$, which so far has not been verified experimentally and could therefore be an artifact.

The main welding induced microstructural change was the full dissolution of intergranular $\mathrm{M}_{23} \mathrm{C}_{6}$ carbides near the fusion line. The width of the carbide-free region varied greatly between mockups, ranging roughly between 100 and $500 \mu \mathrm{m}$ in this work. The transition region with partially dissolved carbides was of comparable width as the carbidefree region. In this transition region, the coarser carbides located within the $\mathrm{Ti}(\mathrm{C}, \mathrm{N})$ bands appeared less affected by the weld. No cracked $\mathrm{M}_{23} \mathrm{C}_{6}$ carbides or $\mathrm{Ti}(\mathrm{C}, \mathrm{N})$ precipitates were observed as a result of welding induced straining.

Since the weld induced plastic straining takes place during cooling after the carbide dissolution, cold worked SA Alloy 690 would be a better representation of this region than cold worked TT Alloy 690. This fits well with the SCC crack growth rates reported in the literature.

\section{Conflict of Interests}

The authors declare that there is no conflict of interests regarding the publication of this paper. 


\section{Acknowledgments}

This work has been performed under the financial support of the energy companies Vattenfall, Fortum, and Eon. The authors would also like to acknowledge EPRI and Ringhals $\mathrm{AB}$ for providing the mockups.

\section{References}

[1] Materials Reliability Program (MRP), Resistance to Primary Water Stress Corrosion Cracking of Alloys 690, 52, and 152 in Pressurized Water Reactors (MRP-111), no. 1009801, EPRI, Palo Alto, Calif, USA; Department of Energy, Washington, DC, USA, 2004.

[2] K. Stiller, J. O. Nilsson, and K. Norring, "Structure, chemistry, and stress corrosion cracking of grain boundaries in alloys 600 and 690," Metallurgical and Materials Transactions A: Physical Metallurgy and Materials Science, vol. 27, no. 2, pp. 327-341, 1996.

[3] T. Yonezawa, K. Onimura, N. Sasaguri et al., "Effect of heat treatment on corrosion resistance of Alloy 690," in Proceedings of the 2nd International Symposium on Environmental Degradation of Materials in Nuclear Power Systems-Water Reactors, pp. 593600, Montery, Calif, USA, September 1985.

[4] J. M. Sarver, J. V. Monter, and B. P. Miglin, "The effect of thermal treatments on the microstructure and SCC behavior of alloy 690," in Proceedings of the 4th International Symposium on Environmental Degradation of Materials in Nuclear Power Systems-Water Reactors, pp. 47-63, Jekyll Island, Ga, USA, August 1989.

[5] D. J. Paraventi and W. C. Moshier, "Alloy 690 SCC growth rate testing," in Proceedings of the EPRI Workshop on Cold Work in Iron and Nickel Base Alloys, R. W. Staehle and J. Gorman, Eds., EPRI Report no. 1016519, EPRI, Palo Alto, Calif, USA, 2007.

[6] M. B. Toloczko, M. J. Olszta, and S. M. Bruemmer, "One dimensional cold rolling effects on stress corrosion crack growth in alloy 690 tubing and plate materials," in Proceedings of the 15th International Conference on Environmental Degradation of Materials in Nuclear Power Systems-Water Reactors, pp. 91106, Colorado Springs, Colo, USA, August 2011.

[7] P. L. Andresen, M. M. Morra, and K. Ahluwalia, "SCC of alloy 690 and its weld metals," in Proceedings of the 15th International Conference on Environmental Degradation of Materials in Nuclear Power Systems-Water Reactors, pp. 161-176, 2012.

[8] A. Sáez-Maderuelo, L. Castro, and G. de Diego, "Plastic strain characterization in austenitic stainless steels and nickel alloys by electron backscatter diffraction," Journal of Nuclear Materials, vol. 416, no. 1-2, pp. 75-79, 2011.

[9] S. M. Bruemmer, M. J. Olszta, M. B. Toloczko, and L. E. Thomas, "Linking grain boundary microstructure to stress corrosion cracking of cold-rolled alloy 690 in pressurized water reactor primary water," Corrosion, vol. 69, no. 10, pp. 953-963, 2013.

[10] K. Arioka, T. Yamada, T. Miyamoto, and T. Terachi, "Dependence of stress corrosion cracking of Alloy 690 on temperature, cold work, and carbide precipitation: role of diffusion of vacancies at crack tips," Corrosion, vol. 67, no. 3, Article ID 035006, 2011.

[11] B. Alexandreanu, Y. Chen, K. Natesan, and B. Shack, "SCC behavior of alloy $690 \mathrm{HAZ}$ in a PWR environment," in Proceedings of the ASME Pressure Vessels and Piping Conference (PVP '11), pp. 385-398, Baltimore, Md, USA, July 2011.
[12] D. R. Tice, S. L. Medway, N. Platts, and J. W. Stairmand, "Crack growth testing on cold worked Alloy 690 in primary water environment," in Proceedings of the 15th International Conference on Environmental Degradation of Materials in Nuclear Power Systems-Water Reactors 2011, pp. 71-78, Colorado Springs, Colo, USA, August 2011.

[13] Q. J. Peng, J. Hou, T. Yonezawa et al., "Environmentally assisted crack growth in one-dimensionally cold worked Alloy 690TT in primary water," Corrosion Science, vol. 57, no. 4, pp. 81-88, 2012.

[14] J.-O. Andersson, T. Helander, L. Höglund, P. Shi, and B. Sundman, "Thermo-Calc \& DICTRA, computational tools for materials science," Calphad, vol. 26, no. 2, pp. 273-312, 2002.

[15] J. J. Kai and M. N. Liu, "The effects of heat treatment on the carbide evolution and the chromium depletion along grain boundary of inconel 690 alloy," Scripta Metallurgica, vol. 23, no. 1, pp. 17-22, 1989.

[16] W. Lengauer, S. Binder, K. Aigner et al., "Solid state properties of group IVb carbonitrides," Journal of Alloys and Compounds, vol. 217, no. 1, pp. 137-147, 1995. 


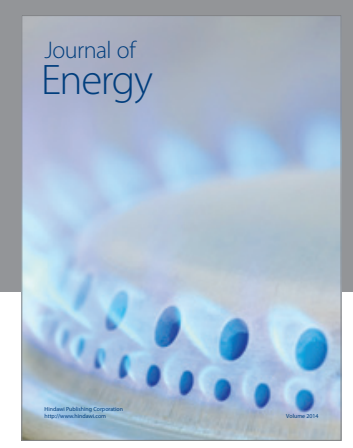

Journal of

Industrial Engineering
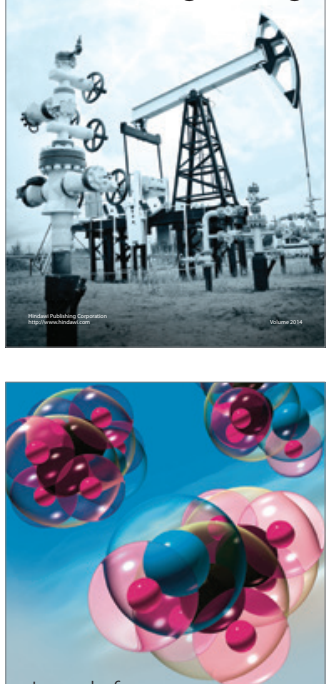

Fuels
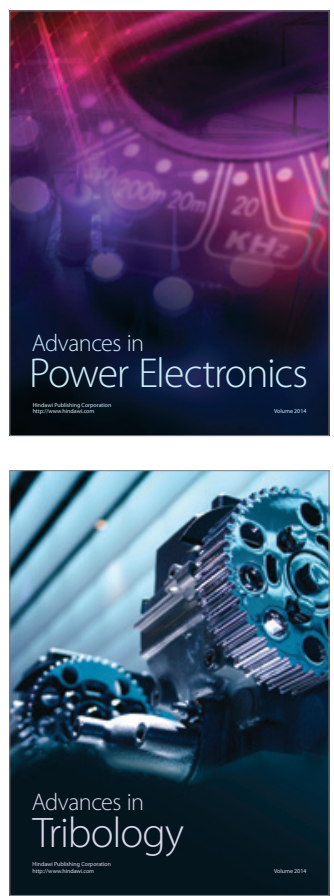

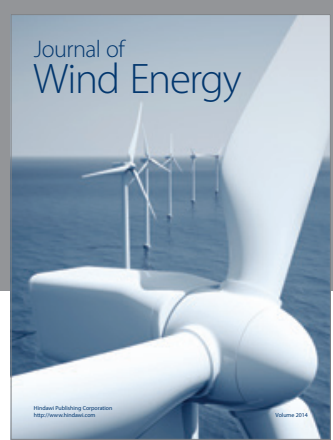

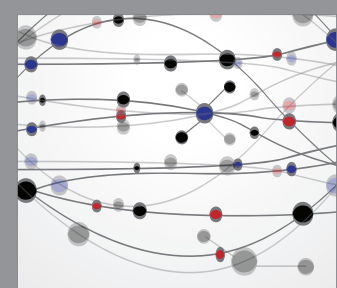

The Scientific World Journal

Submit your manuscripts at http://www.hindawi.com

Journal of

Structures
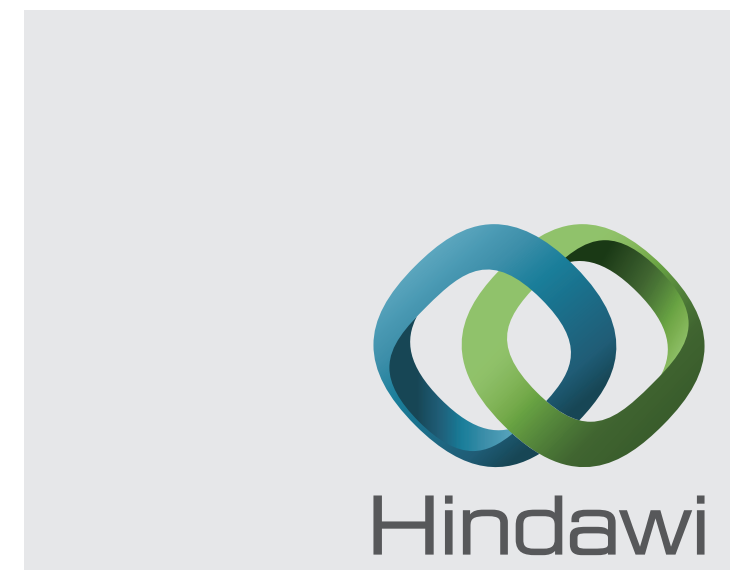

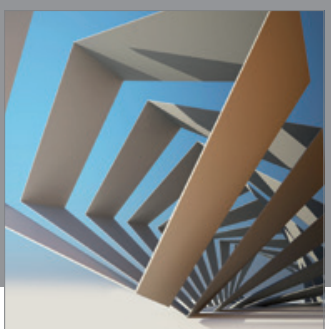

Rotating

Machinery
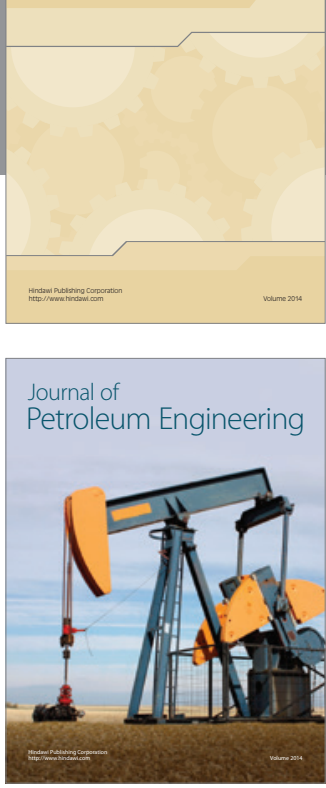

Journal of

Solar Energy
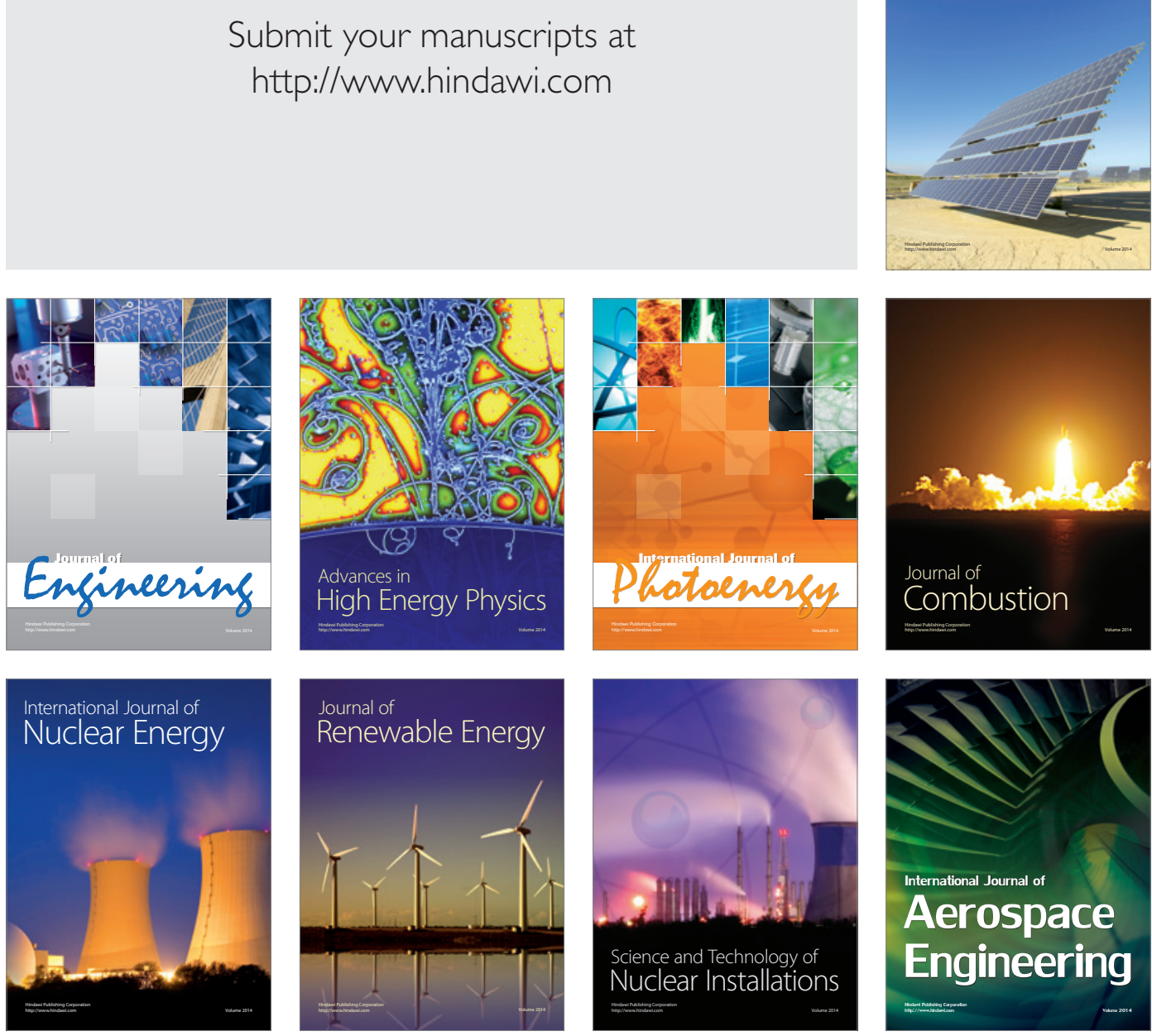